\title{
Laboreal
}

Volume $17 \mathrm{~N}^{\circ} 1$ | 2021

Trabalhar hoje: mudanças, permanências, estratégias, reinvenções

\section{Gestões do trabalho e da saúde pública em tempos de pandemia}

Gestión del trabajo y de la salud pública en tiempos de pandemia

Jussara Brito, Letícia Pessoa Masson e Marcelo Gonçalves Figueiredo

\section{CpenEdition}

\section{Journals}

Edição electrónica

URL: https://journals.openedition.org/laboreal/17544

DOI: $10.4000 /$ laboreal. 17544

ISSN: 1646-5237

\section{Editora}

Universidade do Porto

\section{Refêrencia eletrónica}

Jussara Brito, Letícia Pessoa Masson e Marcelo Gonçalves Figueiredo, «Gestões do trabalho e da saúde pública em tempos de pandemia», Laboreal [Online], Volume $17 N^{0} 1$ | 2021, posto online no dia 18 junho 2021, consultado o 20 junho 2021. URL: http://journals.openedition.org/laboreal/17544 ; DOI: https://doi.org/10.4000/laboreal.17544

Este documento foi criado de forma automática no dia 20 junho 2021

\section{(c) (1) (8)}

Laboreal está licenciado com uma Licença Creative Commons - Atribuição-NãoComercial 4.0 Internacional. 


\title{
Gestões do trabalho e da saúde pública em tempos de pandemia
}

\author{
Gestión del trabajo y de la salud pública en tiempos de pandemia \\ Jussara Brito, Letícia Pessoa Masson e Marcelo Gonçalves Figueiredo
}

1 Em texto de apresentação do Datário do número anterior, Liliana Cunha destaca que o alcance de todo o devir histórico da pandemia de Covid-19 permanece em aberto, propondo as seguintes reflexões: Que história podemos/queremos construir? Qual o lugar e que encontros com o trabalho reserva esta história? Perguntas tão necessárias e instigantes, que só conseguiremos responder, ao nosso ver, a partir de olhares que se complementem e estejam atentos às questões que perpassam a vida no trabalho. É nesse sentido que no Datário desta edição procuramos dar continuidade à reflexão iniciada nos textos de dezembro de 2020, focando agora, particularmente, na realidade brasileira e nas formas como trabalho e saúde pública vêm sendo abordados, geridos e encaminhados no país durante a pandemia.

O primeiro artigo deste dossiê, de autoria de Sandra Caponi, faz um importante registro sobre o trágico "março de 2021", quando se completou um ano da pandemia e, no Brasil, já se havia totalizado mais de 300 mil mortes por Covid-19. A partir das contribuições de Foucault, encontramos em seu texto materiais férteis para entendermos como as estratégias de governo para gerir a pandemia se articulam com saberes, discursos e enunciados científicos. Uma análise que nos remete à esfera do trabalho, quando questiona a falsa dicotomia entre a defesa da vida e a defesa da economia, como se representassem interesses inscritos em polos antagônicos, ao tratar do negacionismo científico. Assim, especificamente no Brasil, são apresentados discursos que negam as evidências científicas a respeito da gravidade do quadro de contaminação, adoecimento e morte, para que certas atividades de trabalho presenciais não sejam interrompidas. Tal postura coloca em risco a vida dos que são obrigados a se deslocar diariamente, de suas casas para os locais de trabalho, através de transportes públicos sempre lotados, como os ônibus, os trens e as vans. Situação que se torna ainda mais crítica devido à não implementação das medidas necessárias ao controle da 
pandemia, como o suporte econômico aos trabalhadores para que possam realizar o isolamento social.

3 Seus argumentos indicam que a exposição sistemática de indivíduos e de grupos a mortes evitáveis pode ser caracterizada como uma gestão necropolítica da pandemia. Com sua contribuição, Caponi coloca o foco sobre o tema dos direitos humanos - que não está dissociado da questão do negacionismo científico, na medida em que a negação dos saberes produzidos no âmbito da ciência representa um obstáculo ao direito à verdade.

4 Ao trazer o exemplo da Nova Zelândia, como contraponto ao caso brasileiro, Caponi adentra em outras questões referentes à gestão da pandemia que também afetam o mundo do trabalho, com destaque para as diferentes consignas que perpassam as biopolíticas adotadas pelos dois países (de um lado, a solidariedade coletiva, de outro, a responsabilização individual pelo controle dos riscos de infecção). Sim, a solidariedade coletiva, como um valor sem dimensão (Schwartz, 2000) vai ter reflexos nos meios de trabalho, assim como sua ausência (e a ênfase em valores do mercado) deixará marcas no corpo dos trabalhadores.

5 Em sequência temos a contribuição de Ana Cláudia Barbosa da Silva-Roosli, cujo texto coloca o foco sobre a data em que a pandemia de Covid foi reconhecida pela Organização Mundial de Saúde - "11 de março de 2020" -, com reflexões sobre seu enfrentamento pelos serviços (e trabalhadores) de saúde. Sua leitura propicia, especialmente, um olhar sobre o trabalho na Atenção Primária à Saúde (APS) no Brasil, alertando que suas potencialidades têm sido desperdiçadas. Não se trata apenas de realçar suas atribuições, mas de evidenciar a diversidade de respostas dadas pelos trabalhadores vinculados à APS às inúmeras questões colocadas pela pandemia nos diferentes territórios, com destaque para as iniciativas da equipe multiprofissional da Estratégia de Saúde da Família. Chama a atenção para as relações de serviço (Zarifian, 2001) que se estabelecem no desenvolvimento de suas atividades, tendo em vista que as ações de saúde não podem ser totalmente antecipadas, sendo concretizadas de modo privilegiado no encontro (imprescritível) com os usuários do sistema.

6 Os interessantes exemplos de modos de reorganização do trabalho em saúde na APS mostram o protagonismo de trabalhadores diretamente envolvidos nas atividades de cuidado, inclusive de pessoas com suspeita de Covid-19, na criação de diferentes estratégias para garantir o atendimento aos usuários e até mesmo para reduzir o nível de propagação da doença. Entre as estratégias indicadas pela autora, podemos citar, já nessa breve introdução, a utilização de mídias sociais com o objetivo de combater a circulação de notícias falsas sobre a doença (ligadas ao negacionismo explorado no texto de Caponi), assim como de fornecer orientações a usuários com risco de Covid-19.

7 A autora nos convoca também a refletir sobre as potencialidades contidas no trabalho dos Agentes Comunitários de Saúde para o controle da pandemia, considerando sua capacidade de mobilização social, resultante da proximidade com as comunidades onde atuam.

8 Entendemos que o artigo de Silva-Roosli representa um convite a olharmos com atenção para as experiências que estão sendo desenvolvidas e para os saberes que vêm sendo instituídos nos serviços de saúde frente ao contexto atual de crise sanitária, implicando em mudanças significativas em seus processos de trabalho e na construção de um patrimônio coletivo. 
O terceiro texto, de Élida Hennington, versa sobre o “28 de abril”, instituído em 2003 como o "Dia mundial em memória às vítimas de acidentes e doenças relacionadas ao trabalho". Uma efeméride recente e pouco conhecida no universo laboral quando comparada ao $1^{\underline{0}}$ de Maio, referência internacionalmente consagrada e que remonta ao século XIX.

No entanto, a disseminação do novo coronavírus pelo planeta e suas repercussões na esfera do trabalho tendem a dar novos contornos à data. A dimensão da catástrofe sanitária, com suas milhões de mortes e sequelas graves, impôs um esforço de excepcional envergadura, tanto no enfrentamento do vírus como no aprendizado correlato ao longo da luta sem precedentes que se sucedeu em escala global.

11 De acordo com a autora, a evolução da pandemia no mundo só fez reforçar o motivo pelo qual a saúde e a segurança devem se consolidar como um direito de todos os que trabalham. Um dos sinais de alerta mais contundentes deu-se a partir da eclosão de surtos da Covid-19 em diferentes categorias profissionais e em distintos processos e locais de trabalho, assim como do crescente número de adoecimentos e mortes de trabalhadores, sobretudo daqueles que atuam na chamada linha de frente e tidos como "essenciais", mas não somente estes.

Nessa direção, todo o empenho pelo reconhecimento da Covid-19 como doença ocupacional poderá ser apreendido como mais uma contribuição relevante na história das lutas por melhores condições de vida e trabalho. Como salienta Hennington, não obstante a evidência científica de que o Sars-Cov-2 causa a Covid-19, em inúmeros casos é difícil atestar a exposição ocupacional, ou ainda, que a patologia foi adquirida em decorrência do trabalho, dada a presença do vírus não apenas no ambiente laboral, mas também em seu exterior.

13 Cabe ressaltar também que o referido texto traz como epígrafe em seu subtítulo "o que aprender com a Covid-19?". E esta indagação evoca algo que nos parece incontornável quando se trata de saúde e segurança, para além do mundo do trabalho, em nível mundial. Como sustentam alguns cientistas renomados, a partir de agora, temos que estar preparados para outros eventos catastróficos, como a pandemia da Covid-19, e riscos de novos desastres globais não devem ser subestimados.

14 Esperamos que a leitura dos textos deste Datário contribua para a reflexão-ação tanto sobre o lugar do trabalho na história desta pandemia, como sobre sua relação com as ações de saúde pública, conforme as provocações feitas por Liliana Cunha (2020). Mesmo se falar no presente sobre o complexo e desalentador momento que vivemos se mostra um limitador do olhar pela falta da perspectiva importante ao aprofundamento das análises, este debruçar-se se coloca de forma urgente, na medida em que se relaciona com a defesa da vida. Neste sentido, por exemplo, é necessário registrar a mais grave das inúmeras estatísticas nefastas do Brasil: em nosso país mais da metade da população não se alimentou como deveria, ou já tinha algum tipo de incerteza quanto ao acesso à alimentação no futuro durante a pandemia de coronavírus [1].

15 Assim, a busca por dar visibilidade ao trabalho deve se dar para além da relativa ampliação que o debate sobre certas ocupações alcançou a partir da pandemia. Tratase, isto sim, de pleitear que esta visibilidade se converta em mudanças efetivas nas nocividades vivenciadas cotidianamente por trabalhadoras e trabalhadores. Pois se de alguma maneira o trabalho pôde ter destaque no debate público do Bem comum, como, por exemplo, uma ampliação da valorização social do SUS (Sistema Único de Saúde) ou 
a emergência de movimentos de trabalhadores por aplicativos (o "Breque dos Apps"), a precariedade das condições de vida e trabalho foi agravada.

\section{BIBLIOGRAFIA}

Cunha, L. (2020). Pandemias e (des)encontros com o trabalho. Laboreal, 16(2). https://doi.org/ 10.4000/laboreal.17408

Schwartz, Y. (2000). Le paradigm ergologique ou un métier de philosophe. Toulouse: Octares.

Zarifian, P. (2001). Objetivo competência. Por uma nova lógica. São Paulo: Atlas.

\section{NOTAS}

1. Fonte: https:// www.brasildefato.com.br/2021/04/13/brasil-tem-125-6-milhoes-de-pessoasem-situacao-de-inseguranca-alimentar-na-pandemia. Pesquisa "Efeitos da pandemia na alimentação e na situação da segurança alimentar no Brasil”, coordenada pelo Grupo de Pesquisa Alimento para Justiça da Universidade Livre de Berlim, na Alemanha, em parceria com a Universidade Federal de Minas Gerais (UFMG) e com a Universidade de Brasília (UnB).

\section{AUTORES}

\section{JUSSARA BRITO}

https://orcid.org/0000-0001-6744-4595

Fundação Oswaldo Cruz, Rua Leopoldo Bulhões, 1480 - Manguinhos, 21041-210, Rio de Janeiro -

RJ, Brasil

jussara@ensp.fiocruz.br

\section{LETÍCIA PESSOA MASSON}

http://orcid.org/0000-0002-5422-286X

Escola Nacional de Saúde Pública da Fundação Oswaldo Cruz (ENSP/FIOCRUZ), Rua Leopoldo

Bulhões, 1480 - Manguinhos, 21041-210, Rio de Janeiro - RJ, Brasil

leticiamasson@ensp.fiocruz.br

\section{MARCELO GONÇALVES FIGUEIREDO}

https://orcid.org/0000-0001-5612-2929

Departamento de Engenharia de Produção da Universidade Federal Fluminense (UFF), Rua Passo 
da Pátria, 156 - São Domingos, 24210-240, Niterói - RJ, Brasil

marceloparada@uol.com.br 